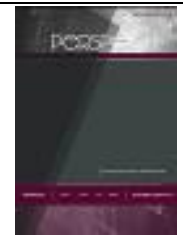

\title{
Komunikasi Nonverbal Guru pada Murid Tunarungu dalam Meningkatkan Kemampuan Berinteraksi Sosial
}

\section{Teacher's Nonverbal Communication for Tunarungu Students in Increasing the Ability Social}

\author{
Inda Wardah Hasibuan, Syafruddin Ritonga* \& Novri \\ Program Studi Ilmu Komunikasi, Fakultas Ilmu Sosial dan Ilmu Politik \\ Universitas Medan Area, Medan
}

Diterima: 27 Mei 2019; Disetujui: 21 September 2019; Diterbitkan: 6 Januari 2020.

\begin{abstract}
Abstrak
Komunikasi merupakan suatu proses sosial yang mendasar dalam kehidupan manusia. Dalam berkomunikasi sering kali menemukan hambatan dalam proses penyampaian pesan. Khususnya berkomunikasi dengan seorang penyandang tunarungu. Tunarungu merupakan individu yang mengalami gangguan pada pendengarannya dan tunarungu biasanya diikuti dengan tunawicara. Gangguan pendengaran ini ada dua jenis yakni gangguan pendengaran total dan gangguan pendengaran sebagian. Dibutuhkan kemampuan khusus seorang guru bagaimana mengajar dan mampu memberikan intruksi dan pengetahuan sesuai dengan kurikulum yang ada disekolah. Salah satunya yaitu penggunaan teknik komunikasi nonverbal. Tujuan dari penelitian ini adalah untuk mengetahui teknik-teknik komunikasi nonverbal bagaimana yang digunakan guru dalam belajar mengajar murid tunarungu untuk meningkatkan kemampuan berinteraksi sosial di Sekolah Dasar Luar Biasa Negeri 027701 Kota Binjai. Metode penelitian yang digunakan adalah pendekatan kualitatif, menjelaskan fenomena dengan mengumpulkan data lalu dianalisa untuk memperoleh kesimpulan. Penelitian dilakukan dengan cara observasi langsung dan wawancara yang melibatkan guru. Dari hasil penelitian ini, dapat dikatakan peran guru dalam menyampaikan komunikasi nonverbal sangat berperan dalam peningkatan kemampuan berinteraksi sosial dan berkomunikasi murid tunarungu.

Kata Kunci: Komunikasi Nonverbal, Tunarungu, Sekolah Dasar Luar Biasa
\end{abstract}

\begin{abstract}
Communication is a basic social process in social life. In communication, we often find many obstacles in delivering the message. Especially delivering a message to a deaf people. Deaf people is a people who can't hear because they have disturbance in hearing and usually they also can't talk. There are 2 types of deaf people, deaf people that can't hear totally and deaf people that can still hear a little. Special skill is needed for a teacher to teach them and can give them instruction and knowledge following the school's curriculum. One of the technic is called Nonverbal Communication. The purpose of this study is for knowing the Nonverbal Communication technics that usually use by the teachers to teach the students to improve their ability to do social interaction in the state extraordinary primary school no 027701 located in te city of Binjai. The method used in this study is qualitative method usually explain the phenomena by collecting the data, and then analyse the data to get the conclusion. This study is done by direct observation and interviews that involving the teachers. And the result of this study, we can say that the role of the teachers in delivering the Nonverbal Communication is very important for the students ability to do interaction and communication
\end{abstract}

Keyword: Nonverbal Communication, Deaf People, Extraordinary Primary School.

How to Cite: Hasibuan, I.W., Ritonga, S. \& Novri (2020). Komunikasi Nonverbal Guru Terhadap Murid Tunarungu dalam Meningkatkan Kemampuan Berinteraksi Sosial. PERSPEKTIF, 9 (1): 19-26.

\footnotetext{
*Corresponding author:

E-mail: syafrrudinritongan@staff.uma.ac.id
} 


\section{PENDAHULUAN}

Anak tunarungu adalah keadaan anak yang mengalami gangguan pada organ bagian pendengarannya sehingga mengakibatkan ketidak mampuan untuk mendengar, mulai dari tingkat yang ringan sampai yang berat sekali yang diklasifikasikan kedalam tuli (deaf) dan kurang dengar (hard of hearing). Mengalami hambatan dalam memproses informasi bahasa melalui pendengarannya dengan atau tanpa menggunakan alat bantu dengar. Sehingga orang yang kurang dengar adalah seseorang yang biasanya menggunakan alat bantu pendengar, sisa pendengarannya cukup memungkinkan untuk keberhasilan memproses informasi bahasa, artinya apabila orang yang kurang dengar tersebut menggunakan hearing aid, ia masih dapat menangkap pembicaraan melalui pendengarannya.

Dampak dari tunarungu adalah terhambatnya komunikasi verbal atau lisan, baik secara ekspresif (berbicara) ataupun reseptif (memahami pembicaraan orang lain), sehingga timbul kesulitan berkomunikasi dengan orang-orang normal yang selalu menggunakan bahasa verbal dalam berinteraksi dan berkomunikasi mereka sehari-hari. Hambatan yang dialami dalam berkomunikasi ini akan berdampak juga pada proses pendidikan, potensi untuk belajar, berinteraksi sosial, dan perkembangan pada anak yang mengalami tunarungu. Mengatasi Shambatanhambatan tersebut anak yang mengalami gangguan pada pendengarannya atau yang sering kita dengar dengan kata tunarungu membutuhkan perlakuan khusus untuk mengembangkan kemampuan berbahasa dan kemampuan untuk berbicara, sehingga dapat meminimalisasi dampak dari ketunarunguan yang dialaminya.

Mengalami tunarungu bukan hanya mengakibatkan tidak berkembangnya kemampuan berbicara bahkan lebih, paling besar adalah terbatasnya kemampuan berbahasa. Terhambatnya kemampuan berbahasa anak tunarungu, maka akan berimplikasi pada kebutuhan khusus mereka untuk mengembangkan kemampuan berbahasa dengan menggunakan metode pembelajaran khusus anak tunarungu, pada dasarnya setiap anak tunarungu dapat dikemban kemampuan berbahasa dan berbicaranya dengan berbagai perlakuan khusus dan fasilitas kelas yang sesuai dengan kebutuhannya.

Definisi tunarungu diatas dapat disimpulkan bahwa anak tunarungu adalah anak yang memiliki gangguan dalam pendengarannya. Baik secara keseluruhan maupun masih memiliki sisa pendengaran. Meskipun anak tunarungu sudah diberikan alat bantu pendengar, tetap saja anak tunarungu masih memerlukan pelayanan pendidikan khusus sehingga anak-anak tunarungu berinteraksi sosial dengan baik seperti anak-anak normal lainnya.

Menurut pasal 15 UU No. 20 tahun 2003 tentang sistem Pendidikan Nasional, bahwa jenis pendidikan bagi anak berkebutuhan khusus adalah pendidikan khusus. Pasal 32 UU No. 20 tahun 2003 bahwa pendidikan khusus merupakan pendidikan bagi peserta didik yang memiliki tingkat kesulitan dalam mengikuti proses pembelajaran karena kelainan fisik, emosional, mental, sosial, dan memiliki potensi kecerdasan dan bakat istimewa. Salah satu cara untuk membantu anak tunarungu dalam berinteraksi sosial adalah dengan menggunakan bahasa isyarat atau komunikasi nonverbal.

Melatih anak tunarungu dengan menggunakan bahasa isyarat akan sangat mempermudah dalam berinteraksi sosial dilingkungannya. Jika komunikasi berjalan dengan efektif maka akan terwujud suatu interaksi sosial yang baik antara anak tunarungu dengan orang-orang normal yang berada disekitarnya sehari-hari. Komunikasi merupakan salah satu aspek terpenting dalam kehidupan sehari-hari. 
Komunikasi nonverbal merupakan suatu proses interaksi antara dua atau lebih individu yang mencoba saling mempengaruhi dalam hal ide, sikap, pengetahuan, tingkah laku. Komunikasi nonverbal juga untuk meluapkan atau mengekspresikan segala emosi yang mereka alami khususnya anak tunarungu. kegiatan komunikasi yang dilakukan bukan dengan kata-kata ataupun suara tetapi melalui gerakan-gerakan anggota tubuh, suatu objek, dan penggunaan simbol-simbol.

Komunikasi nonverbal sangat efektif dan berhasil jika anak penyandang tunarungu mampu menggunakannya ketika berinteraksi sosial. Faktor yang paling penting dalam keberhasilan komuniksi nonverbal ini adalah bagaimana kedua individu yang terlibat dalam komunikasi memiliki pandangan atau memaknai pesan nonverbal yang disampaikan oleh lawan komunikasi anak tunarungu tersebut.

Dalam hal meningkatkan kemampuan murid tunarungu untuk dapat berinteraksi dan berkomunikasi dengan baik sangat dibutuhkan kemampuan seorang guru tentang bagaimana mengajar, mendekatkan diri kepada murid penyandang tunarungu dan mampu menangani murid, guru berperan memberikan istruksi dalam upaya memberikan pengetahuan dengan kurikulum yang ada. Kemampuan berkomunikasi seorang guru mendorong terjadinya komunikasi yang efektif.

\section{METODE PENELITIAN}

Jenis penelitian ini adalah yang menggunakan pendekatan kualitatif dengan menggunakan metode penelitian deskriptif kualitatif. Metode kualitatif sebagai prosedur penelitian yang menghasilkan data deskriptif berupa katakata tertulis atau lisan dari orang-orang dan perilaku yang dapat diamati. Metode penentuan sumber data atau informan dalam penelitian ini adalah menggunakan metode snowball sampling. Metode ini merupakan metode penentuan sampel atau informan dengan cara memilih satu atau dua orang informan awal.

Untuk memperoleh data dari lapangan, peneliti menggunakan beberapa metode pengumpulan data sesuai dengan jenis penelitian, adapun metode pengumpulan data sebagai berikut: 1) Wawancara; 2) Observasi; 3). Dokumentasi

Sesuai dengan jenis metode penelitian yang digunakan yaitu penelitian deskriptif dengan pendekatan kualitatif. Maka dalam penelitian ini analisis data yang digunakan yaitu: 1) Reduksi data; 2) Penyajian data; 3) Penarikan kesimpulan.

\section{HASIL DAN PEMBAHASAN SDLB NEGERI 027701 Kota Binjai}

027701. SDLB Negeri 027701 Kota Binjai yang berada di Jl. Dewi Sartika 1/167 Komplek Handayani Jati Karya Kecamatan Binjai Utara, lokasi sekolah berada dipedalaman ini adalah sekolah dasar luar biasa yang didirikan oleh pemerintah. Sekolah ini dibangun untuk mendidik dan membimbing anak-anak yang berkebutuhan khusus, seperti tunanetra, tunarungu, tunagrahita, tunadaksa, dan autis. Sekolah ini mulai beroprasi tahun 1984 dan pada saat itu sekolah belum memiliki murid. Guru yang ada pada saat itu hanya ada 3 orang, ketika itu para guru bertugas untuk langsung turun mencari murid ke kelurahan dan kekampung-kampung, dan waktu itu murid yang diterima pada saat mendaftar tidak ada batasan mengenai usia. Pada saat itu juga sekolah belum memiliki kepala sekolah, pada akhir tahun 1984 barulah ada ala sekolah di Sekolah Dasar Luar Biasa Negeri 027701 Kota Binjai yang bernama bapak Sugian Rikardus Purba, dan pada saat ini yang menjadi kepala sekolah di Sekolah Dasar Luar Biasa Negeri

027702 Kota Binjai adalah ibu Dalipah Spd dimana ibu Dalipah telah mengajar di Sekolah dari awal tahun 1984. 
Dan dua belas orang guru yang mengajar di Sekolah Dasar Luar Biasa Negeri

027701 Kota Binjai yaitu guru yang mengajar kelas tunarungu, tunagrahita, tunanetra, guru pendidikan agama islam dan agama kristen. Adanya sekolah SDLB Negeri 027701 Kota Binjai ini sama halnya seperti sekolah dasar biasa lainnya yaitu untuk mengoptimalkan potensi-potensi yang dimiliki oleh anak-anak berkebutuhan khusus, dan agar mereka bisa mandiri dalam hidupnya meskipun memiliki kekurangan. Hal ini sesuai dengan Undang-Undang No. 20 Tahun 2003 tentang Sistem Pendidikan Nasional

\section{Gambaran Umum Responden}

Responden yang pertama bernama Umaimah Zahra anak dari bapak Pujiono dan ibu Sumarni. Zahra adalah anak ke empat dari empat bersaudara. Saat ini Zahra berusia sepuluh tahun dan duduk dikelas tiga Sekolah Dasar. Zahra adalah anak yang mengalami kekurangan ganda yaitu mengalami tunarungu dan kurangnya penglihatannya. Umaimah Zahra pada saat lahir dengan keadaan normal dan tingkah laku seperti anak normal pada umumnya. Ketika diusia delapan bulan Zahra mengalami sakit panas yang tinggi dan mulailah Zahra mengalami katarak dini, pada saat Zahra berusia satu tahun barulah orang tua Zahra menyadari bahwa Zahra mengalami tunarungu dan gangguan pada penglihatannya. Diusia satu tahun Zahra telah melakukan operasi pada kedua matanya karena katarak dini yang dialaminya. Mengetahui keadaan mata Zahra yang mengalami katarak dini orangtua Zahrapun mengikuti saran dari dokter agar Zahra segera untuk melakukan operasi pada matanya, jika tidak melakukan operasi pada maka perkembangan Zahra mengalami idiot, tetapi paska operasi Zahra tidak ada perubahan pada penglihatannya dan mengalami emosional yang tinggi.
Ketika kita melihat Zahra dari keadaan fisiknya tentusaja tidak terlihat memiliki kekurangan apapun. Sebelum Zahra sekolah, saat bergaul dengan orangorang yang ada di lingkungan rumahnya dan mencoba untuk berinteraksi dengan orang lain itu sangat sulit karena tunarungu dan kurangnya penglihatan yang dialami oleh Zahra. Ketika berada dirumah orang tua Zahra menggunakan bahasa isyarat dengan Zahra. Dalam bidang belajar dikelas Zahra termasuk kurang karena daya tanggapnya tidak sama dengan teman-teman dikelasnya. Kurangnya penglihatan yang dialami Zahra menjadi hambatan Zahra untuk belajar. Pelajaran yang diterima Zahra dikelas lebih mudah dari pada teman-temannya yang berada di kelas itu merupakan hambatan dari kurangnya penglihatan yang dialaminya sehingga Zahra sulit untuk mengikuti semua pelajaran yang ada dikelasnya. Dalam berinteraksi dengan orang baru juga Zahra mengalami kesulitan, dan biasanya ketika Zahra bertemu dengan orang yang baru ia temui dia akan diam dan merasa sedikit risih dan tidak nyaman. Pada setiap harinya ketika sekolah Zahra selalu diantar dan ditunggu oleh ibunya sampai pulang sekolah.

Annisa Syafitri lahir pada tanggal 17 Mei 2005, Annisa adalah putri dari bapak Ribowo Sono dan Ibu Karmilah. Annisa sekarang ini berumur tiga belas tahun dan duduk dikelas enam Sekolah Dasar. Orang tua Annisa menyadari Annisa mengalami tunarungu ketika berumur 3 bulan. Ketika Annisa masih di dalam kandungan ibunya selalu mengalami pendaharan, ibu

Annisa juga pernah jatuh ketika Annisa di dalam kandungan. Dalam riwayat keluarga Annisa tidak ada yang mengalami tunarungu.

Dari usia tujuh tahun Annisa sudah disekolahkan oleh orang tuanya dengan harapan agar Annisa memperoleh pendidikan seperti anak-anak normal lainnya. Penalaran Annisa dalam belajar sangatlah baik, dia dengan mudah 
mengikuti pelajaran yang ada dikelasnya. Annisa saat ini sudah mampu membaca, paham akan abjad jari, dan juga pelajaran yang ada dikelasnya. Penalaran baik yang ia miliki mampu membantunya untuk berinteraksi dengan orang disekitarnya, bahkan Annisa mampu berinteraksi dan berkomunikasi dengan orang normal. Annisa mampu memahami pembicaraan yang dilakukan oleh orang normal dengan melihat dan memahami gerak bibir orang yang berkomunikasi dengannya. Setiap harinya Annisa diantar oleh ibunya kesekolah bahkan ibu Annisa setiap hari menunggu Annisa sampai selesai sekolah setiap harinya. Annisa anak yang pandai bergaul dengan orang-orang yang ada disekitarnya, ketika jam istirahat Annisa bermain dengan teman-temannya.

Hasil penelitian ini diperoleh dari hasil pengumpulan data di lapangan yang dilakukan oleh peneliti dengan narasumber yang telah ditetapkan, dengan cara wawancara, observasi berpartisipasi serta melakukan dokumentasi. Dalam melakukan wawancara ini, peneliti membutuhkan waktu selama dua bulan lebih, dimulai dari Februari 2018 hingga pertengahan April 2018. Objek dalam penelitian ini adalah dua orang murid tunarungu yaitu Umaimah Zahra dan Annisa Safitri. Dan yang menjadi informan pada penelitian ini merupakan orang yang mengetahui secara mendalam kegiatan yang diteliti yaitu dua orang guru yang khusus mengajari murid tunarungu di Sekolah Dasar Luar Biasa Negeri 027701 Kota Binjai.

\section{Komunikasi Guru pada Murid}

Berdasarkan hasil observasi dan wawancara langsung yang dilakukan di lapangan dan sesuai dengan pedoman wawancara, maka peneliti dapat menyimpulkan hasil dari penelitiannya sebagai berikut ini:

Untuk melakukan pendekatan dengan Zahra ibu guru harus memulainya dengan berkomunikasi. Bertanya mengenai hal-hal dasar, yang paling utama dimana harus duduk berdampingan dengan Zahra atau bertatap muka, memperlakukan Zahra sebagaimana ibu guru dengan anak kandungnya sendiri, mengelus-elus kepalanya, tanyakan namanya siapa, rumahnya dimana, kalau Zahra tidak paham dengan apa yang bicarakan oleh ibu guru, disitulah ibu guru menggunakan bahasa isyarat sebagai tambahan untuk mempermudah Zahra memahami apa yang dimaksud oleh gurunya. Melakukuan pengaplikasian gerak bibir dan bahasa isyarat sangat membantu untuk berkomunikasi dengan Zahra, jadi Zahra akan mengerti apa yang maksud dimaksud oleh guru tersebut.

Komunikasi nonverbal yang dilakukan guru ketika berkomunikasi dengan Zahra yaitu menggunakan bahasa isyarat, dan bahasa isyat yang bisa dipahami dan dimengerti oleh Zahra, karena bahasa isyarat yang digunakan gurunya seperti biasa dengan murid-murid tunarungu yang ada dikelas belum tentu Zahra mampu memahami seluruhnya bahasa isyarat tersebut. Ibu Marini selaku gurunya harus memahami Zahra terlebihdahulu, misalnya ketika menyuruh Zahra untuk makan, gurunya mengatakan selain mengandalkan gerak bibir dengan Zahra saya juga harus iringin dengan bahasa isyarat dengan gerak tangan. Jadi ketika berkomunikasi dengan Zahra kita harus benar-benar melakukan bahasa isyarat tertentu yang membuat Zahra mudah memahaminya. Komunikasi dengan Zahra kita harus berusaha agar dia memahami apa yang kita maksud.

Yang menjadi hambatan guru dalam melakukan komunikasi dan berinteraksi dengan Zahra itu biasanya karena sifat Zahra yang mudah sekali berubah dan seringkali Zahra merajuk, ketika dari rumah Zahra sudah mengalami mood yang kurang baik untuk berkomunikasi dengan Zahra disekolahpun menjadi sulit, Zahra tidak akan mau merespon siapapun ketika dia sedang mengalami mood yang tidak 
baik, Zahra memilih untuk diam. Bahkan orangtuanya sendiripun sulit berkomunikasi dengan Zahra ketika kondisi hati Zahra sedang tidak baik.

Meningkatkan rasa percaya diri Zahra dalam berkomunikasi dengan orang lain dan menangani kondisi psikologi Zahra bu Marini selalu berkomunikasi dan berkompromi dengan orang tua Zahra, memberikan pemahaman kepada orang tua Zahra harus bagaimana dalam menyikapi Zahra, guru dan orang tua Zahra saling membantu satu sama lain untuk memahami Zahra. Jadi ketika bu Marini tidak memahami Zahra, dengan bekerja sama dengan orang tuanya dan mengetahui perkembangan Zahra ketika diluar lingkungan sekolah itu mempermudah bu Marini untuk melakukan sesuatu untuk lebih meningkatkan rasa percaya diri Zahra dalam berinteraksi dengan orang lain dan bagaimana kondisi psikologi Zahra.

Untuk metode pembelajaran Zahra dalam meningkatkan kemampuan berinteraksi sosial dalam belajar mengajar Zahra dikelasnya dan untuk berkomunikasi dengannya bisa dikatakan berbeda atau khusus karena Zahra mengalami tunarungu dan tunagrahita, berbeda dengan murid- murid yang ada dikelasnya, Jadi dalam mengajari Zahra dan berkomunikasi dengan dia pun saya lebih ekstra dengan bahasa isyarat tidak sama dengan teman satu kelasnya.

Cara yang dilakukan ibu Marini dalam meningkatkatkan kemampuan Zahra untuk bisa berinteraksi dan berkomunikasi dengan orang lain itu terlebih dahulu bu Marini membiasakan Zahra untuk memahami gerak bibir, menambah kosa kata Zahra dengan menggunakan media gambar, benda-benda yang ada disekitar sekolah, dan menggunakan gerak bibir serta diiringi dengan bahasa isyarat. Ibu Marini mengatakan untuk berkomunikasi dan berinteraksi dengan orang lain Zahra masi belum mampu, tunarungu dan tunagrahita yang dialami Zahra membuat penalaran Zahra kurang. Ketika Zahra bertemu dengan orang yang baru iya kenal Zahra juga merasa malu dan tiada mau berinteraksi dan sulit untuk Zahra mengerti apa yang dimaksud oleh seseorang tersebut.

Annisa Syafitri melakukan pendekatan agar dapat berinteraksi dan berkomunikasi dengan Annisa yang dilakukan terlebih dahulu mencari tahu apa yang menjadi kesukaan Annisa, kita ajak dia bermain, bercerita mengenai teman-temannya disekolah dan lingkungan rumahnya, menanyakan tentang keluarganya, ketika dirumah Annisa dengan siapa saja, menanyakan kesenangan Annisa apa, dan menanyakan pekerjaan apa yang dibebankan seharihari kepadanya ketika sedang berada dirumah. Tanyakan dahulu semua tentang ruang lingkup keluarganya dirumah. Setelah itu tanyakan tentang bagaimana dia ketika dikelasnya, mengenai temantemannya siapa saja yang dia suka di dalam kelasnya, pelajaran apa yang dia suka. Dengan mengetahui semua hal tentang Annisa memudahkan dalam melakukan pendekatan dan berkomunikasi.

Komunikasi Nonverbal yang dilakukan dengan Annisa selalu mengutamakan gerak bibir bukan bahasa isyarat, bahasa isyarat hanya menjadi tambahan ketika Annisa tidak mengerti apa yang dimaksud, selalu berupaya bagaimana Annisa bisa mengeluarkan suaranya, dapat memahami apa yang kita inginkan. Ketika dia mampu memahaminya gerak bibir yang selalu digunakan. Ketika dia mengalami kelemahan dalam komunikasinya, ketika Annisa tidak memahami barulah kita gunakan bahasa isyarat, tetapi selalu diupayakan untuk menggunakan bahasa bibir atau oral seperti orang normal dalam berkomunikasi.

Adanya hambatan dalam

berinteraksi dan berkomunikasi itu 
sudah pasti ada, hambatannya itu dari tingkat kemampuan Annisa sendiri, karena tidak dapat mendengar sangat berpengaruh dalam perkembangan itu yang menjadi hambatan. Kurang memahami bendahara kata ataupun tata bahasa. Contohnya apa yang kita mau apa yang kita maksud belum tentu dia memahaminya itulah yang menjadi hambatanya. Kenapa itu, karena kemampuan berbahasanya kurang jadi kita tingkatkanlah dibagian mana dia sulit untuk berkomunikasi baik saat belajar misalnya pada bagian abjad, konsonan, kita harus berusaha untuk meningkatkan kemampuannya. Karena dia tidak mendengar dalam pengucapan kata be dan pe itu hampir sama disitulah guru harus bisa membuat Nissa mengerti. Kondisi yang tidak seperti anak normal lainnya tentu saja tetap ada penanganan khusus. Mengajak Annisa berkomunikasi secara pribadi tidak secara classical. Dengan begitukan lebih mudah dalam berinteraksi dan berkomunikasi. Dengan berkomunikasi secara pribadi dapat mengetahui dimana kekurangannya kita melakukan pendekatan secara pribadi disitulah nanti kita bisa sama sama memahi.

Menumbuhkan rasa percaya diri Annisa untuk dapat berinteraksi dengan orang lain, gurunya memberikan motivasi kepada Annisa harus mampu seperti teman-temannya terutama harus mampu seperti anak normal lainnya. Untuk membantu Annisa gurunya selalu memberi latihan ke pada Annisa, guru Annisa selalu menyuruh Annisa tampil untuk maju kedepan kelas menyampaikan apa yang dia rasakan, dan memimpin doa dikelasnya hal-hal yang seperti itu dapat meningkatkan kepercayaan dirinya.

Metode pembelajaran yang gunakan guru dalam meningkatkan kemampuan berinteraksi dan berkomunikasi Annisa dalam biasanya metode ceramah itu sudah tidak lagi, jadi dengan memberikan tugastugas, menggunakan metode demonstrasi, metode komunikasi. Memberikan tugas kepada Annisa kita melakukan komunikasi disitu Nissa belajar untuk memahami apa yang di maksud, dan menyuruh untuk maju kedepan kelas untuk menyampaikan pesan kepada teman- temannya itu akan membuat Annisa salah satu cara untuk meningkatkan kemampuan Nissa. Hambatan Annisa dalam berkomunikasi dan berinteraksi adalah dia kurang bisa memahami teman-temannya, Annisa tidak terlalu perduli mengenai teman-temannya itu menjadi hambatan Annisa dalam berkomunikasi dan berinteraksi dengan teman-temannya di ruang kelas. Dan Annisa juga sulit dalam mengeluarkan suara meskipun Nissa memahami sesuatu tetapi Annisa sedikit sulit untuk mengeluarkan suaranya dan penekanan suaranya Nissa juga sedikit sulit. Peran guru sangat penting dalam perkembangan kemampuan Annisa agar dapat berinteraksi dengan orang-orang normal lainnya yang ada disekitarnya. Menurut gurunya kalau yang dia lihat Annisa sudah termasuk mampu untuk berinteraksi dengan orang-orang normal yang ada disekitarmya, dibandingkan dengan teman-temannya yang lain.

$$
\text { Setelah melakukan penelitian }
$$

komunikasi nonverbal guru terhadap murid tunarungu untuk meningkatkan kemampuan berinteraksi sosial di SDLB Negeri 027701 Kota Binjai, peneliti mengkaitkan hasil penelitiannya dengan teori akomodasi dan teknik komunikasi nonverbal yang berkaitan dengan bahasa tubuh yang digunakan guru ketika mengajar. Dimana teori akomodasi menjelaskan tentang menyesuaikan perilaku komunikasi kita dengan perilaku komunikasi orang lain seperti halnya berkomunikasi dengan anak penyandang tunarungu. Kelompok Anak penyandang tunarungu mereka menggunakan bahasa atau sistem komunikasi nonverbal yang sama. Berbeda dengan orang normal lainnya, mungkin anak-anak tunarungu akan membedakan dirinya dari orang lain 
atau mereka akan berusaha untuk beradaptasi. Peneliti telah melihat bagaimana upaya guru beradaptasi dengan murid tunarungu dengan menggunakan komunikasi nonverbal yang dipahami oleh murid-murid tunarungu. Dimana antara murid tunarungu dan guru sudah saling memahami akan apa yang mereka komunikasikan. Dengan komunikasi total yang dilakukan guru yaitu bahasa verbal atau lisan, menggunakan Bahasa isyarat atau bahasa nonverbal. Dimana untuk tahap awal guru memperkenalkan bahasa abjad jari yaitu huruf A sampai Z kepada murid ini untuk membantu mempermudah mengenal bahasa.

Ada lima tipe yang dikelompokkan oleh Ekman dan Friesen yaitu teknik komunikasi nonverbal, dari lima tipe peneliti mengkaitkan hasil dari penelitian. Dimana semua perilaku nonverbal ini tergantung pada sumber perbuatan, penandaan atau koding dan penggunaannya. Berikut adalah lima tipe prilaku komunikasi: Emblem, Ilustrator, Adaptor, Regulator, Penunjukan perasaan (affect display)

\section{SIMPULAN}

Komunikasi nonverbal yang dilakukan guru dalam meningkatkan kemampuan berinteraksi murid tunarungu adalah menggabungkan antara komunikasi verbal dan nonverbal. Penggabungan antara komunikasi verbal dan nonverbal merupakan komunikasi yang efektif diantara kaum tunarungu melalui sisa pendengaran, isyarat, ejaan abzad jari, dan membaca ujaran atau gerak bibir. Perilaku nonverbal yang secara langsung menerjemahkan kata atau ungkapan. Teknik yang digunakan guru untuk menguji kepintaran murid, memberitahukan larangan dengan menggunakan teknik emblim. komunikasi yang digunakan oleh murid Sekolah Dasar
Luar Biasa Negeri 027701 Kota Binjai dalam berinteraksi ada dua bentuk yang pertama nonverbal yaitu Emblem, Ilustator, Regulator, Penunjuk Perasaan, dan yang ke dua melakukan penggabungan komunikasi verbal dan nonverbal.

\section{DAFTAR PUSTAKA}

Afrizal, M.A, (2014). Metode Penelitian Kualitatif. Jakatra: PT Raja Grafindo Persada.

Afrizal, M.A, (2014). Metode Penelitian Kualitatif: Sebuah Upaya Mendukung Penggunaan Penelitian Kualitatif Dalam Berbagai Disiplin Ilmu. Jakarta: Pt Raja Grafindo Persada.

Arikunto. (2006). Manajemen Penelitian. Jakarta: Rhineka Cipta.

Budyatna, M. \& Leila M.G. (2011). Teori Komunikasi Antar Pribadi. Jakarta: Kencana Prenada Media Group.

Cangara, H. (2013). Perancanaan dan Strategi Komunikasi. Jakarta: PT. Raja Grafindo Persada. Devito, J. 1997. Komunikasi Antar Manusia. Jakarta: profesional book

Effendi, M. (2006). Pengantar Psikopedagogik Anak Berkelainan. Jakarta: Bumi Kasara.

Effendy, O.U. (2005). Ilmu Teori, dan Filsafat Komunikasi. Bandung: Citra Aditya Bakti.

Hardjana, A.M. (2003). Komunikasi Intrapersonal \& Interpersonal. Yogyakarta: kanisius.

Kriyantono, R. (2010). Teknik Praktik Riset Komunikasi. Jakarta: Kencana. (2006). Teknik Praktis Riset Komunikasi. Jakarta: Kencana.

Morissan. (2013). Teori Komunikasi Individu Hingga Massa. Jakarta: Kencana.

Muhammad, A. (2007). Komunikasi Organisasi. Jakarta: PT. Bumi Perkasa Murtie, A. 2016. Ensiklopedi Anak Berkebutuhan Khusus. Jogjakarta: Maxima

Noor, J. (2011). Metodologi Penelitian: Skripsi, Tesis, Disertasi, Dan Karya Ilmiah. Jakarta: Kencana Prenada Media Group

Somantri, S. (2007). Psikologi Anak Luar Biasa. Bandung: PT. Rafika Aditama

Soekanto, S. (2002). Sosiologi: suatu pengantar. Jakarta: Raja Persada.

Sugiyono. (2008). Metode Penelitian Kuantitatf Kualitatif dan R\&D. Bandung: Alfabeta.

Turner, R. (2008). Pengantar Teori Komunikasi Analisis Dan Aplikasi. Jakarta: Salemba Humanika.

Undang-Undang No. 20 Tahun Tentang Sistem Pendidikan Nasional. 